\title{
The future fertility of highly educated women: the role of educational composition shifts and labor market barriers
}

\section{Alícia Adserà*}

The childbearing patterns of highly educated women will be a key factor in the evolution of fertility - not only in developed countries, but in rapidly developing economies, where fertility rates are quickly declining to below replacement levels, and where educational attainment is rising rapidly as well. The answer to the question posed above is likely a function of multiple factors that are related, among other things, to fertility preferences, couple formation dynamics, labor market institutions, and gender roles; as the other contributions to the debate in this volume discuss. Here, I want to focus on three points: (1) who the college-educated are today; (2) what we know about the fertility preferences and the actual fertility of highly educated women, and about whether the mismatch between fertility preferences and realized fertility differs depending on educational attainment; and (3) whether highly educated women experience barriers in achieving their fertility goals, or their personal target (as Lutz discusses in his contribution).

First, to answer the question of whether highly educated women will have more children in the future, it is important to observe the current distribution of educational attainment across developed countries, to describe the shifts in its composition, and explore how these changes can affect our understanding of who is educated. In recent decades, educational expansion across the most developed countries, particularly in areas that traditionally had low levels of educational attainment, such as Southern Europe, has dramatically changed the profiles of young adults. Figure 1 shows the shares of 30-34-year-olds (i.e., adults of prime childbearing ages) in selected European countries who have tertiary education. The average for the European Union in 2016 is 44 percent among women and 34 percent among men. A majority of women have attained some level of tertiary education in many countries, including in Belgium, Sweden, the UK, Switzerland, the Netherlands, Lithuania, Germany, and Poland. In Italy and Spain, close to one-half of women have tertiary education. Furthermore, in all of the countries

\footnotetext{
* Alícia Adserà, Woodrow Wilson School of Public and International Affairs, A29 Julis Romo Rabinowitz Building, Princeton University, Princeton, NJ 08544, USA

Email: adsera@princeton.edu
} 
Figure 1:

Tertiary educational attainment of 30-34-year-olds by sex in selected European countries, 2016

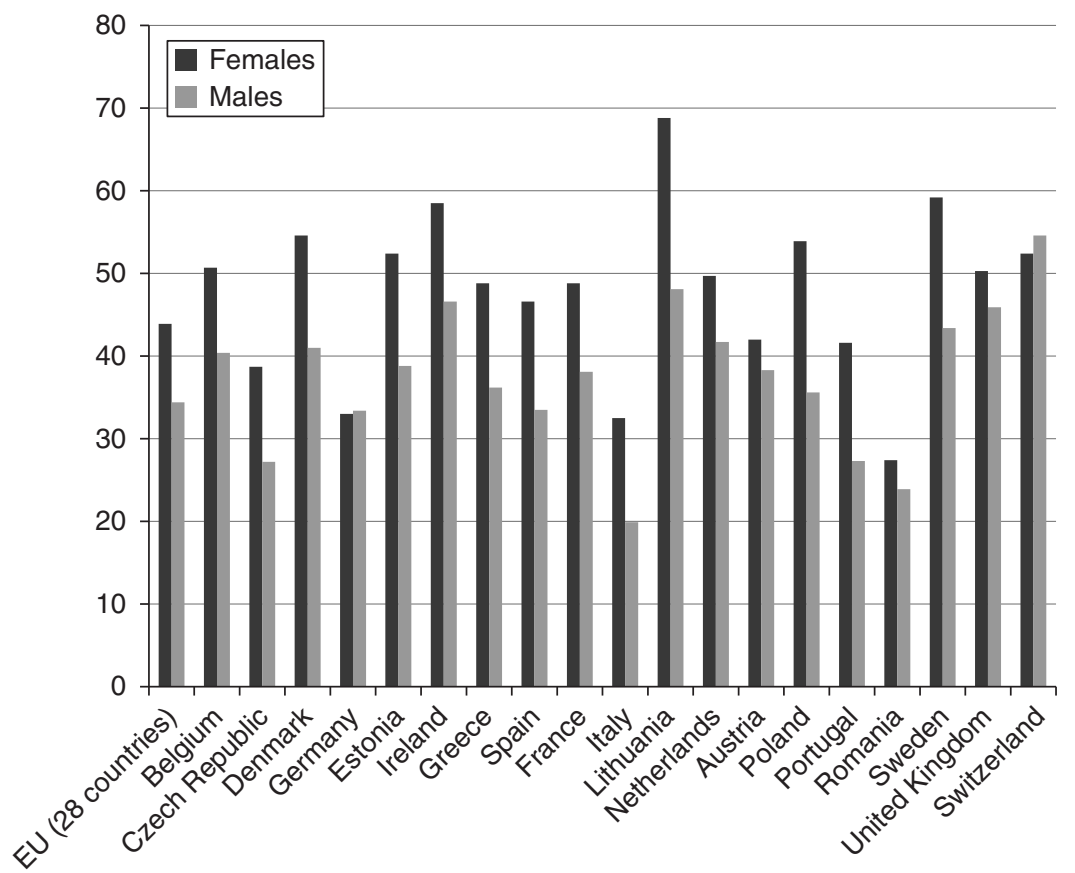

Note: Here, tertiary educational attainment refers to having completed ISCED (International Standard Classification of Education) 2011 levels 5-8 for data from 2014 onward, and to having completed ISCED 1997 levels 5-6 for data up to 2013. The indicator is based on the EU Labour Force Survey. Author's calculations based on Eurostat data, accessed in April 2017 at http://ec.europa.eu/eurostat/.

in Figure 1 except for Switzerland, greater shares of women than of men have higher education. As Van Bavel (2012) carefully lays out in his overview paper on the reversal of gender inequality, this trend could have important consequences for fertility and partnership formation.

Moreover, the observed large compositional changes in Figure 1 imply that highly educated women now represent a larger share of the population - and that, as a result, they may be less selected - than their counterparts in previous generations. ${ }^{1}$ Thus, highly educated women may be more representative of the population as a whole

\footnotetext{
1 For example, at the turn of the 20th century, around 30 percent of US women who graduated from college between 1900 and 1920 never married; and among those who married, around 30 percent remained childless (Goldin 2004). However, only around 21 percent of US women born in 1970 who are in the top quartile of educational attainment have remained childless (Bailey et al. 2014).
} 
in terms of their fertility and work preferences. Indeed, today less educated women may be more selected than highly educated women.

Therefore, when thinking of the behavior of "highly educated" women, we may need to consider what metric of education we want to employ: i.e., absolute or relative education. The right metric may vary by the realm of analysis (such as fertility, partnership formation, or labor market attachment).

On the one hand, having a high level of education, as measured by the absolute level of attainment, has important implications for the life course. Having better cognitive abilities is generally associated with lower morbidity, longer life, lower risks of engaging in adverse behavior, and better general skills for adapting to the changing environment (Lutz and Skirbekk 2014). Thus, as Lutz notes in his discussion piece, highly educated women may have better tools for reaching their life goals in many dimensions, such as fertility. Having higher educational attainment and lower morbidity (particularly at the top of the income/educational distribution) are also associated with increases in life expectancy. When thinking about human capital investments, women are likely to recognize that they will live more years without than with young children in the house, and that the potential returns to those investments are likely to be high. As I emphasize below, society as a whole should take into account this transformation of women's life-cycle, and should enact policies accordingly.

However, the expected change in the selection among the pool of highly educated women opens up the research question of whether we should use relative measures of education or some other index to understand behavior within that group. Some possible alternatives include years of schooling, educational quartiles (as in Bailey et al. (2014)), field of study, and occupational prestige (which implies labor market participation). On the one hand, due to shifting patterns in employment, education has come to play an increasingly important role in determining compensation levels (Autor 2014). On the other, unlike a few decades ago, having a college degree is no longer a passport to getting a stable and high-paying job. The income distribution of workers with college degrees has widened, partly because of the growth in the numbers of tertiary educated workers in the economy, and partly because of the heterogeneity in their fields of education. Whereas the best educated in certain fields are at the top of the income distribution, it is not unusual for college-educated workers (particularly young adults) to earn very meager salaries in very unstable jobs. In Spain, for example, these workers are called mileuristas, or "thousand euros." Moreover, some jobs traditionally performed by individuals with varying degrees of post-secondary education are now disappearing ("jobs in the middle").

Consistent with the trend in educational attainment just described, across rich countries, the share of women with children who are highly educated has been rising. Currently, the majority of new mothers in the United States have some years of college (although not all are college graduates). Figure 2 shows the shares of mothers of infants by education and marital status in the US in 1960 and in 2011. In 1960, the share of women who had an infant and some college was 18 percent, while the share of women who had an infant and a high school education or less 
Figure 2:

Shares of mothers of infants by education and marital status in the US, 1960 and 2011

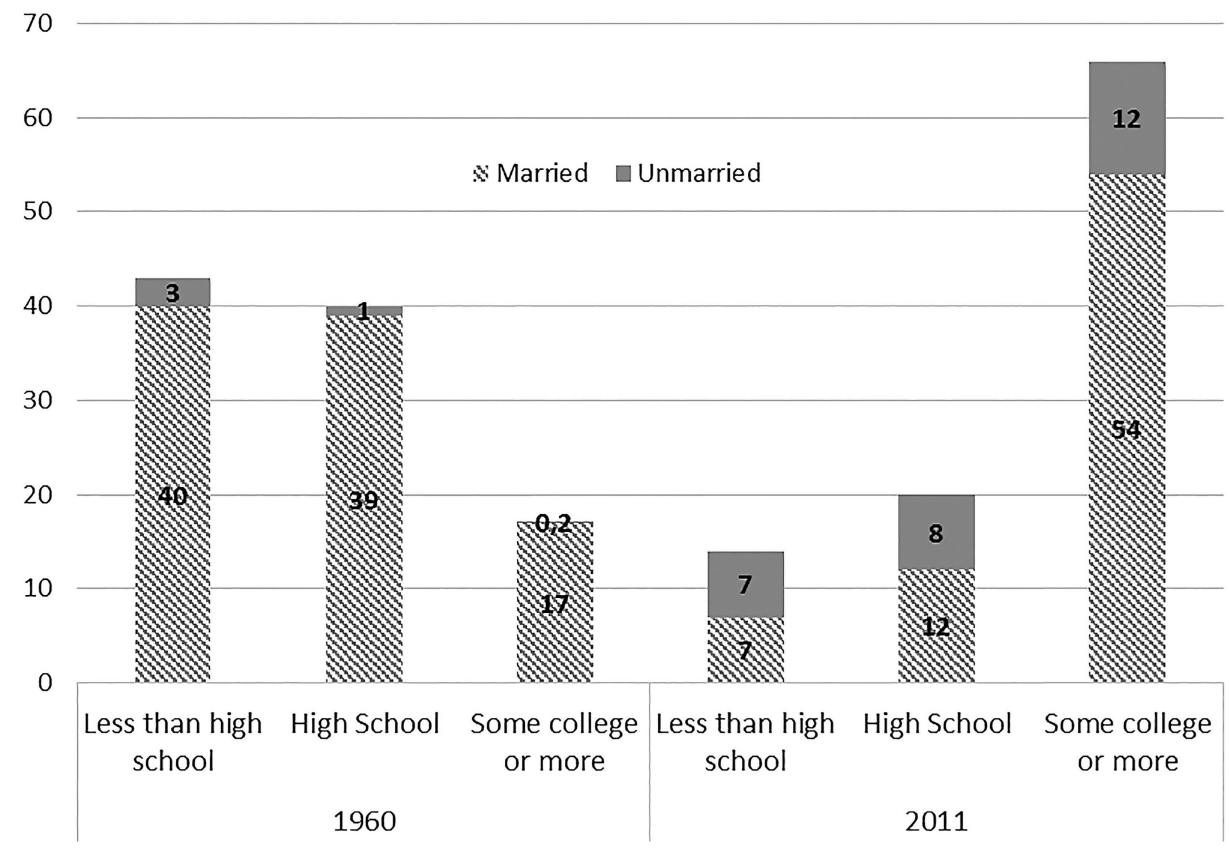

Source: Pew Research Center (2013), using data from the 2011 American Community Survey (ACS) (1\% national random sample of the population available in Integrated Public Use Microdata Series (IPUMS; available at https://usa.ipums.org/usa/sampdesc.shtml)) and the 1960 census (1\% national random sample of the population available in IPUMS).

was 82 percent. In 2011, the respective shares for these two groups were 66 and 34 percent. (Pew Research Center 2013). Recent Eurostat data show a similar trend in many European countries.

Second, we need to look at the fertility preferences and the behavior of the highly educated. The fertility intentions of tertiary educated women differ little from those of less educated women, and are still around the replacement level in most countries (Sobotka et al. 2015). Recent studies have found a positive relationship between intended fertility and overall educational attainment in a given country (Testa 2014). As Lutz and Testa (this volume) argue, the gap between intentions and actual fertility for highly educated women is larger in some countries than in others (see also European Fertility Datasheet (Sobotka et al. 2015)). However, this pattern may be shifting as a result of recent changes in the labor market. Bailey et al. (2014) showed that in the US, the differences in the completed fertility of women in the lowest quartile and in the highest quartile of the educational distribution have been closing among the most recent cohorts.

These latest trends seem to indicate that fertility preferences vary little by educational level; and that in some countries, the childbearing intentions of highly 
educated women appear to have converged and even surpassed the intentions of less educated women. The fertility rates of different educational groups seem to be converging as well. The decrease in selection among the pool of highly educated women, and the effects of the recent economic crises, which hit the least educated particularly hard, may have contributed to the shrinking of the gap.

Finally, the question of whether this convergence and flattening of the educational gradient in fertility is temporary remains open. Labor market data show that it is becoming more difficult for men (and women) with low or medium levels of education to get "good" jobs. In many developed countries, growing numbers of young people are returning to (or staying in) their parents' home. Today, many young adults are unable to become independent or have children unless they are in a two-income household. Thus, women in a stable, high-earning partnership should find it easier than women who are not in such a partnership to realize their personal fertility goals.

The data displayed in Figure 2 show that in 2011, 66 percent of all mothers had some college; 54 percent were married and had some college, and 12 percent were unmarried and had some college. In the same year, 19 percent of mothers had a high school diploma or less and were married, and 15 percent of mothers had a high school diploma or less and were unmarried. The educational gradient in outof-wedlock births is relatively similar across Europe, with less educated women being more likely than highly educated women to have a non-marital birth (PerelliHarris et al. 2010). Van Bavel notes in his contribution (this volume) that the rates of long-term union formation have increased more among the highly educated than among the less educated. Lundberg and Pollak (2014) argued that highly educated individuals prefer to have children within marriage as they want to ensure that their partner is committed to investing in the children. In the European context, being in a stable partnership could play the same role. Moreover, as Esping-Andersen notes in his contribution, gender roles are evolving, and are changing more rapidly among the highly educated than among the less educated. Thus, a highly educated spouse may be more likely than a less educated one to support his wife in combining career and family.

Women's low earnings may reduce their ability to afford to have their intended number of children, especially when faced with high child care costs. Across the rich countries, the gender wage gap is still pervasive, and can be partly explained by women's cumulative experience levels and main sectors of employment (Blau and Kahn 2016). Figure 3 shows the shares of students by field of tertiary education and by gender across the EU 28 countries. The more technical fields, such as engineering and information and communication technologies, are clearly dominated by men. Jobs in these technical fields have some of the highest average rates of pay. These gender differences are later amplified in men's and women's professional careers. Conversely, the arts and humanities, education, health, and the social sciences tend to be dominated by women. In some of the highest paying sectors, putting in long hours is rewarded with higher rates of hourly pay. This implies that highly educated women employed in these sectors who want to combine family and work 
Figure 3:

Shares of students enrolled in tertiary education by field of study and gender across the EU 28 countries, 2014

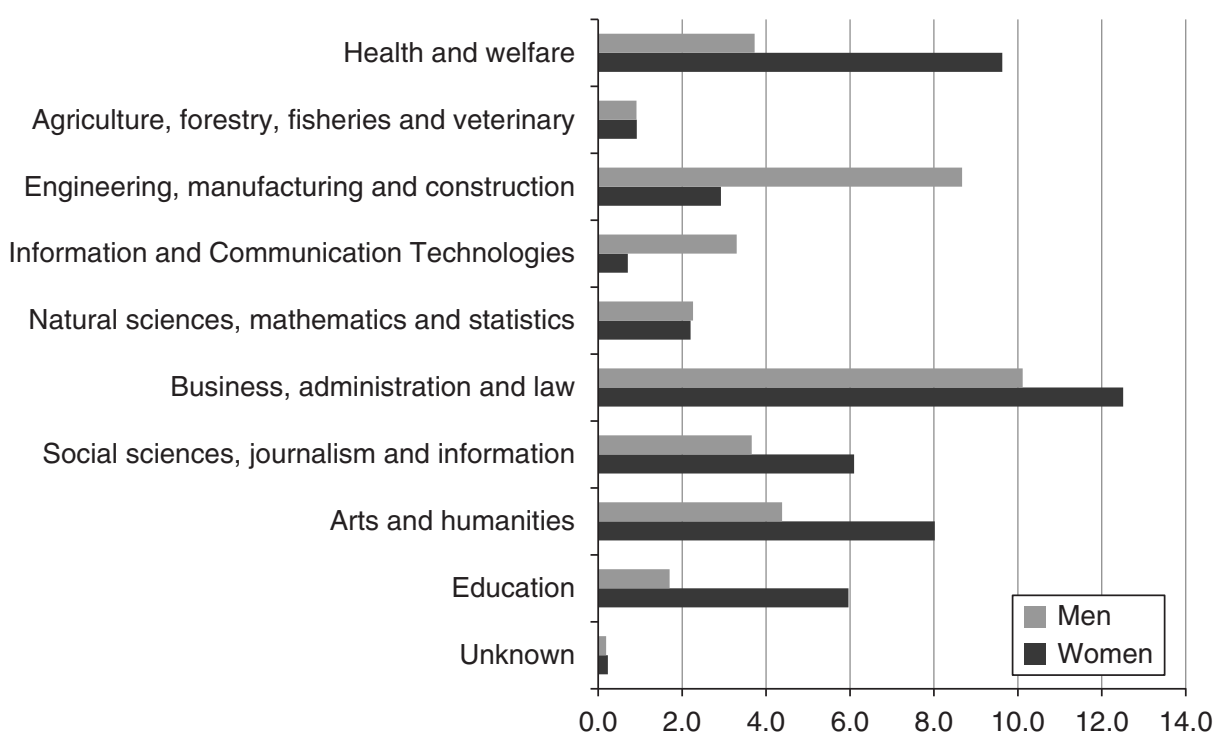

Source: Author's calculations based on Eurostat data, accessed March 2017 at http://ec.europa.eu/eurostat/, file_[educ_uoe_enrt03].

are heavily penalized. Other sectors, including education and health, tend to be more accommodating to women with children, offering them greater security combined with more flexible schedules and more generous periods of leave. In many countries, some of these positions are in the public sector. Thus, it is not surprising that women tend to choose those professions (Figure 3).

Labor market institutions matter (Adserà 2011); women should not have to work exclusively in the protected public sector (as was initially the case in the pioneering Nordic countries) or in highly regulated sectors in order to combine work and family. Public policy should level the playing field for women in a broader sense. Since life expectancy is becoming longer as educational levels are rising, countries are increasingly able to take full advantage of women's skills. Policy-makers should thus enact policies with a longer time horizon. Testa (2014) found that in European countries where relatively large shares of women are highly educated, the gap between desired and realized fertility is relatively small. This is likely because these countries have favorable labor market conditions and strong welfare state institutions (which are possibly the product of lobbying by highly educated pioneers and far-sighted policy-makers) that offer women a better bargain. This trend has also been mentioned by Van Bavel (2012).

To sum up, I believe that the flattening of the educational gradient will be a relatively persistent phenomenon, but that there is a need for labor market policies 
that could remove or lower the barriers that highly educated women face in achieving their relatively high fertility goals.

\section{References}

Adserà, A. 2011. Where Are The Babies? Labor market conditions and fertility in Europe. European Journal of Population 27: 1-32.

Autor D. H. 2014. Skills, education, and the rise of earnings inequality among the "other 99 percent". Science 344(6186): 843-51

Bailey, Martha J., Melanie Guldi and Brad J. Hershbein 2014. Is there a case for a second demographic transition? Three distinctive features of the post-1960 U.S. fertility decline. In Human capital in history: The American record, eds Boustan, Frydman, and Margo, 273-312. Chicago, IL: University of Chicago Press.

Blau, Francine D. and Lawrence M. Kahn 2016. The gender wage gap: extent, trends, and explanations. IZA DP No. 9656, January.

Goldin, C. 2004. The long road to the fast track: Career and family. Annals of the American Academy of Political and Social Science 596(1): 20-35.

Lundberg, Shelly and Robert A. Pollak 2014. Cohabitation and the uneven retreat from marriage in the U.S., 1950-2010, NBER Chapters. In Human capital in history: The American record, pp. 241-272. National Bureau of Economic Research, Inc.

Lutz, W. and V. Skirbekk 2014. How education drives demography and knowledge informs projections (Chapter 2). In World population and human capital in the twenty-first century, eds W. Lutz, W. P. Butz, and S. KC. Oxford University Press.

Perelli-Harris, B., W. Sigle-Rushton, M. Kreyenfeld, T. Lappegård, R. Keizer, and C. Berghammer 2010. The educational gradient of childbearing within cohabitation in Europe. Population and Development Review 36(4), 775-801.

Pew Research Center 2013. Long-term trend accelerates since recession. record share of new mothers are college educated. http://www.pewsocialtrends.org/2013/05/10/ record-share-of-new-mothers-are-college-educated/ Retrieved November 2015.

Sobotka, T., K. Zeman, M. Potančoková, J. Eder, Z. Brzozowska, É. Beaujouan and A. Matysiak 2015. European fertility datasheet 2015. Vienna Institute of Demography/Wittgenstein Centre for Demography and Global Human Capital (IIASA, VID/ÖAW, WU).

Testa, Maria Rita 2014. On the positive correlation between education and fertility intentions in Europe: Individual-and-country-level evidence. Advances in Life Course Research 21: $28-42$.

Van Bavel, J. 2012. The reversal of gender inequality in education, union formation and fertility in Europe. Vienna Yearbook of Population Research 2012: 127-154. 
